\title{
PUBLICIDADE COMO PEDAGOGIA CULTURAL: REPRESENTAÇÕES DE GÊNERO NAS CAMPANHAS DE JEAN-PAUL GAULTIER
}

\author{
PUBLICITY AS CULTURAL PEDAGOGY: GENDER REPRESENTATIONS IN THE JEAN-PAUL GAULTIER CAMPAIGNS \\ PUBLICIDAD COMO PEDAGOGÍA CULTURAL: REPRESENTACIONES DE GÉNERO EM LAS CAMPAÑAS DE JEAN- \\ PAUL GAULTIER
}

SILVA JUNIOR, Alcidesio Oliveira da 1

FÉLIX, Jeane ${ }^{2}$

\section{RESUMO}

Compreendendo que os processos educativos têm se estendido para além de uma reflexão meramente voltada aos espaços formalizados de educação, este artigo lança luz à publicidade, concebendo-a como um artefato cultural que constitui identidades. Por um viés amparado na interface entre os Estudos Culturais e os Estudos de Gênero, procuramos aqui identificar, à luz da análise cultural, as representações de gênero encontradas em 04 imagens das campanhas dos perfumes Le Male e Classique de Jean-Paul Gaultier, apontando que estas, baseando-se em uma ideia de masculinidade viril e potente, bem como em uma feminilidade doce e sensual, carregam identidades estereotipadas de gênero que educam os sujeitos através da ideia de uma naturalização de certos comportamentos atribuídos, dicotomicamente, aos homems e às mulheres.

Palavras-chave: Pedagogia Cultural. Estudos Culturais. Publicidade. Gênero.

\section{ABSTRACT}

Understanding that educational processes have extended beyond a reflection merely focused on formalized spaces of education, this article sheds light on advertising, conceiving it as a cultural artifact that constitutes identities. Through a bias based on the interface between Cultural Studies and Gender Studies, we try to identify, in the light of cultural analysis, the gender representations found in 04 images of the campaigns of the fragrances Le Male and Classique by Jean-Paul Gaultier, pointing out that These, based on an idea of virile and potent masculinity, as well as a sweet and sensual femininity, carry stereotyped gender identities that educate the subjects through the idea of a naturalization of certain behaviors attributed, dichotomically, to men and women.

Keywords: Cultural pedagogy. Cultural Studies. Publicity. Gender.

\section{RESUMEN}

Entendiendo que los procesos educativos se han extendido más allá de una reflexión meramente enfocada en espacios formales de educación, este artículo arroja luz sobre la publicidad, concibiéndola como un artefacto cultural que constituye identidades. A través de un sesgo basado en la interfaz entre Estudios Culturales y Estudios de Género, tratamos de identificar, a la luz del análisis cultural, las representaciones de género encontradas en 04 imágenes de las campañas de las fragancias Le Male y Classique de Jean-Paul Gaultier, señalando que Estos, basados en una idea de masculinidad viril y potente, así como una feminidad dulce y sensual, llevan identidades de género estereotipadas que educan a los sujetos a través de la idea de una naturalización de ciertos comportamientos atribuidos, dicotómicamente, a hombres y mujeres.

Palabras clave: Pedagogía cultural. Estudios culturales. Publicidad. Género.

\footnotetext{
${ }^{1}$ Universidade Federal da Paraíba.

2 Universidade Federal da Paraíba.
} 


\section{INTRODUÇÃO}

Imersos em um mundo de significações em jogo, no qual disputas em torno da constituição de sujeitos se movem em diferentes instâncias, reflexões que buscam lançar luz a estes esquemas de poder, entrelaçados em discursos reguladores de formas estereotipadas de ser e estar no mundo se acentuam. Assim, mais que os espaços educacionais formais, os processos educativos desenvolvidos pelas mais variadas instâncias sociais passam a ser entendidos como artefatos culturais, balizadores de novas formas de pensar, novos posicionamentos no mundo, se configurando, portanto, como pedagogias. Cinema, música, arquitetura, moda, entre outros produtores/produtos de discursos, se movimentam como ferramentas de ressignificação de valores, de emoções, de comportamentos diversos, em outros termos, como pedagogias culturais.

Neste texto, buscamos refletir sobre as chamadas "pedagogias culturais" (STEIMBERG, 1997) e suas múltiplas formas de constituição de identidades, compreendendo que os artefatos midiáticos ampliam os debates sobre os processos educativos para além dos espaços tradicionais de educação formal, como escolas e universidades. Ao conceber a mídia como um artefato que atua na fabricação de sujeitos, podemos aqui, desenvolver reflexões que auxiliem as pesquisas no campo das Ciências Humanas, particularmente da Educação, a desembocarem em novas percepções que tratem da relação entre as subjetividades e a cultura.

Assim, procuramos neste artigo identificar, à luz da análise cultural, as representações de masculinidade(s) e feminilidade(s) encontradas nas campanhas de publicidade dos perfumes da grife do renomado estilista francês Jean-Paul Gaultier. A escolha do seu nome tem a ver com a forma com que Gaultier revolucionou o mundo da moda nos anos 1990, com suas criações para a popstar Madonna, além de ter utilizado pessoas consideradas fora do padrão de beleza em seus desfiles, especialmente quando falamos da década em questão, com modelos tatuadas/os, gordos/as e idosos/as, trazendo sobre o estilista muitas críticas, mas, também, popularidade entre os/as artistas do universo pop mundial.

No site oficial da grife francesa (www.jeanpaulgaultier.com) podemos encontrar três categorias denominadas de acordo com o gênero, na perspectiva da empresa. A linha masculina Les Males com os perfumes Le Male Eau de Toilette, UItra Male Eau de Toilette Intense, Le Male Essence de Parfume - Le Male In the Navy, a linha feminina Classique com os perfumes Classique Eau de Toilette, Classique Eau de Parfum, Classique Essence de Parfum e o Classique Cabaret Eau de Parfum, além de uma outra categoria não definida como masculina e/ou feminina, a linha Scandal com os perfumes Scandal a Paris Eau de Toilette, Scandal Eau de Parfum e Scandal by night Eau de Parfum Intense.

Para a problemática das representações de gênero deste artigo, nos lançamos aos aportes dos Estudos Culturais (STEINGBERG, 1997; SILVA, 2014; AMARAL; 2004; COSTA \& ANDRADE, 2015), com alguns apontamentos sobre mídia, destacando a publicidade (KELLNER, 2012; DANIEL \& AMODEO, 2014; SILVA \& BITTENCOURT, 2008), ampliando as reflexões sobre os processos culturais de significação, bem como dos Estudos de Gênero (BARROS, 2007; BUTLER, 2011, 2018; LAURETIS, 1987; SEFFNER, 2003; ZAGO, 2009, SABAT, 2001). Assim, para fins deste texto, 
utilizaremos em nossas análises 04 (quatro) imagens da campanha publicitária dos perfumes Le Male e Classique de Jean-Paul Gaultier, que servirão de material para a análise cultural aqui pretendida.

\title{
OS CORPOS COMO TEXTOS: A PUBLICIDADE EM QUESTÃO
}

Ao falar de corpos, somos costumeiramente levados ao senso comum de pensarmos em uma constituição puramente biológica, fisiológica, na qual mecanismos atuam com funcionalidades determinadas para a sustentação da vida. Pensamos em braços, pernas, olhos, bocas, pensamos em órgãos internos... que guardam em si funções que vão da reprodução sexual à alimentação. Todavia, pensar nos corpos, como textos e como linguagem, amplia nossa visão a respeito das manifestações discursivas que permeiam e constroem esta materialidade, produzindo formas de representação dos sujeitos, regulações de comportamentos, estilos de vida, além de padrões de beleza a serem seguidos em uma sociedade antenada às demandas do consumo. Nessa direção, podemos dizer que o corpo é uma construção cultural. Dizer isso, obviamente, não retira do corpo sua materialidade biológica, mas associa a ela uma gama de sentidos que só são possíveis no âmbito de uma determinada cultura. Segundo Cleide Campello (1996, p. 67):

\begin{abstract}
É no corpo que se vai gravando a história da cultura a que aquele corpo pertence. Afinal, desde o momento de seu nascimento, o homem ${ }^{3}$ é moldado para pertencer a um dado grupo, com regras éticas e estéticas mais ou menos fixas. Assim, num dado espaço-tempo histórico, a cultura exige que as mulheres de um determinado grupo social sejam gordas, num outro momento que sejam muito magras [...] e outras inúmeras e variáveis regras a serem seguidas pelos componentes de um determinado grupo de cultura, pois quem constrói para o corpo a noção de identidade, a noção de sujeito, é a noção da presença do Outro.
\end{abstract}

No corpo são inscritas, gravadas, as marcas culturais que marcham de acordo com a ordem discursiva de uma determinada época e em determinados contextos sociais. São marcas que advém dos tempos, das conjunturas econômicas, dos grupos sociais e étnicos (GOELLNER, 2013), enfim, todo um entorno que confere a esta materialidade algum significado cultural, algum sentido dado socialmente. É através dos corpos que os sujeitos se expressam para conseguirem coisas, para se relacionarem, para se movimentarem em códigos sociais e culturais que são lidos e interpretados pelo/a outro/a. Segundo Campello (1996, p. 64), "o corpo tem textos que brotam das emoções, como a paixão e a inveja, o medo e o amor" revelando, portanto, sinalizações que são/foram interpeladas a todo o momento por meio das práticas de significação e de linguagem.

Assim, visto que é nesse corpo que os valores de uma sociedade específica se inscrevem (DAOLIO, 1995), podemos considerar que estes atuam como suporte para as representações dos sujeitos nos mais variados meios, seja nos seus registros em currículos formais de ensino, seja na mídia, apresentando-se como pedagogias culturais ao educar os sujeitos em formas específicas de se comportarem, constituírem suas identidades e valores.

\footnotetext{
${ }^{3}$ Ressaltamos nossa discordância com o termo "homem" como categoria totalizadora do ser humano utilizado pela autora em seu texto, na medida em que tomamos a pluralidade de formas de existência exercidas e (re)inventadas, cotidianamente, pelos diferentes sujeitos.
} 
Aqui, tomamos a publicidade, em específico, como uma pedagogia cultural ao entender, juntamente com Shirley Steinberg que "a pedagogia cultural está estruturada pela dinâmica comercial, por forças que se impõem a todos os aspectos de nossas vidas privadas e das vidas de nossos/as filhos/as" (1997, p. 102). Compreendendo os artefatos midiáticos como potência educativa, Steinberg estende a sua reflexão sobre estas novas formas pedagógicas que circulam na sociedade e que atuam produzindo novas formas de consumo. Entendemos tais considerações para além do consumo de um produto em si, abarcando também o consumo de corpos aceitáveis, interessantes e hegemônicos na sociedade, os quais mobilizam pessoas a buscarem, de diversas formas, encaixarem-se (ou resistirem) aos padrões que Ihes são socialmente impostos. De acordo com Costa \& Andrade (2015, p. 845):

Diversificados espaços e artefatos culturais estão hoje implicados tanto nas formas como as pessoas pensam e agem sobre si mesmas e sobre o mundo que as cerca como nas escolhas que fazem e nas maneiras como organizam suas vidas. Nas complexas sociedades do mundo globalizado, pedagogias são praticadas também por jornais, programas de TV peças publicitárias, filmes, revistas, sites e inúmeros outros artefatos que atravessam a vida contemporânea.

Uma reflexão crítica sobre o papel da mídia como espaço pedagógico precisa ser encarada com mais profundidade para que se problematize, nesses lugares, os jogos de poder que se enredam, pois a pedagogia, as formas educativas que atravessam os sujeitos, não são mais exclusivas das práticas escolares, religiosas e familiares (COSTA \& ANDRADE, 2015). Segundo Marise Basso Amaral, através de leituras de Henry Giroux (2004, p. 150), é preciso que se desenvolva:

\footnotetext{
Uma pedagogia que se preocupe com o desenvolvimento de um alfabetismo crítico da mídia, o qual possibilite a discussão das políticas de identidade e políticas de representação articuladas nas diferentes instâncias culturais com as quais interagimos normalmente, precisa reconhecer, primeiramente, estes locais como espaços legítimos de produção e divulgação de conhecimento. [Grifo da autora].
}

A publicidade, como uma das práticas comunicacionais mais presentes nas mídias e no cotidiano em nossos dias, representa um papel importantíssimo nesta pedagogização dos sujeitos. Esta, além de vender produtos e marcas, também apresenta os padrões (supostamente) ideais nas representações dos corpos, produzindo sujeitos e corpos abjetos na medida em que fogem daquilo que deles é esperado socialmente. Segundo Kellner (2012, p. 108), "[...] a publicidade é um texto social importante e um indicador social que fornece um repositório de informações a respeito de tendências sociais, de modas, de valores contemporâneos". Aqui cabe perguntar: o que pode ser lido através destes corpos na publicidade? Quais são os textos que circulam construindo esta(s) materialidade(s) mutável(is)? Sobre a publicidade, Amaral argumenta que (2004, p. 152),

Assim como as demais imagens veiculadas pela mídia, as imagens publicitárias são saturadas de posições e oposições que impõem ressignificações. A publicidade ensina uma visão de mundo, valores e aqueles comportamentos que são ou não, socialmente aceitáveis.

Estas valorações determinadas pelos discursos (SILVA, 2014) fomentam as práticas de sustentação das hegemonias, sejam elas de gênero, raça, identidades sexuais, ou outras categorias de constituição dos sujeitos, silenciando formas não-hegemônicas, lançando-as à marginalidade, fomentando ou potencializando diversas formas de opressão. Valorações estas percebidas na imensa 
quantidade de imagens publicitárias que atravessam o nosso cotidano, agindo sobre as formas dos sujeitos (se) verem e (se) pensarem (n)o mundo.

De fato, desde o momento em que acordamos com rádios despertadores e ligamos a televisão com os noticiários da manhã até nossos últimos momentos de consciência, à noite, com os filmes ou programas de entrevista noturnos, encontramo-nos imersos num oceano de imagens, numa cultura saturada por uma flora e fauna constituídas de espécies variadas de imagens, espécies que a teoria cultural contemporânea apenas começou a classificar (KELLNER, 2012, p. 104).

Cabe destacar que tomamos discurso, aqui, na perspectiva de Michel Foucault, para quem o discurso vai além das coisas ditas, desenvolvendo-se, também, por meio das práticas, que sempre se constituem por meio das relações de saber-poder. Foucault (1986, p. 56) indica que "o discurso não é uma estreita superfície de contato, ou de confronto, entre uma realidade e uma língua, o intrincamento entre um léxico e uma experiência". Para o autor, "analisando os próprios discursos, vemos se desfazerem os laços aparentemente tão fortes entre as palavras e as coisas, e destacar-se um conjunto de regras, próprias da prática discursiva".

\section{AS REPRESENTAÇÕES DE GÊNERO NA PUBLICIDADE DOS PERFUMES JEAN-PAUL GAULTIER}

Sendo a publicidade uma “ação, manifestação, representação social e coletiva” (DANIEL \& AMODEO, 2014, p. 246) que se inscreve como prática cultural de uma determinada sociedade, constituída por discursos e regras específicas - visto que, segundo o filósofo Michel Foucault as regularidades discursivas estão dentro de uma ordem do que é permitido em determinado momento da história (FOUCAULT, 1996) - podemos identificar nas campanhas do perfume Le Male e Classique, da grife francesa Jean-Paul Gaultier, formas de masculinidade e de feminilidade que se inscrevem na ordem do hegemônico, fundando-se em práticas atuantes nas subjetividades diversas.

Aqui tomamos as considerações de leitura crítica de imagens de Douglas Kellner ao argumentar que "ler imagens criticamente implica aprender como apreciar, decodificar e interpretar imagens, analisando tanto a forma como elas são construídas e operam em nossas vidas quanto o conteúdo que elas comunicam em situações concretas” (2012, p. 106, grifos do autor). Ao pensar as imagens como constructos culturais, carregados de representações de gênero condizentes com os interesses hegemônicos, fazer a sua leitura crítica requer evidenciar os elementos concebidos enquanto naturais, mas dotados de significações históricas e culturais proeminentes.

Segundo Louro (1997), representações são formas culturais de nos referirmos a determinados sujeitos ou grupos sociais. Na perspectiva pós-estruturalista, com a qual operamos, importa-nos colocar em destaque e em dúvida as apresentações de uma realidade que é construída por meio desses discursos de representação, entendendo-as como resultado de disputas de poder em torno da produção de sentidos e seus efeitos sobre os sujeitos. Com base em Silva (1996), Guacira Lopes Louro destaca que:

Os modos como os grupos sociais são representados podem nos indicar o quanto esses grupos exercitam o poder, podem nos apontar quem é, mais frequentemente, "objeto" ou "sujeito da representação". Em outras palavras, podem nos apontar quem utiliza o poder para representar o outro e quem é apenas representado (LOURO, 1997, p. 102, grifos da autora) 
Percebemos, então, que há uma reforçada tentativa de naturalização de comportamentos esperados tanto em relação às mulheres, quanto aos homens nas campanhas dos perfumes Le Male e Classique de Jean-Paul Gaultier. Para Butler (2011, p. 87), "o gênero é aquilo que é assumido, invariavelmente, sob coação, diária e incessantemente, com inquietação e prazer". Gênero se constituiria, pois, como práticas performativas, repetidas até tornarem-se naturalizadas. Assim, é importante, segundo a autora, que estas performances de gênero sejam repetidas, objetivando, portanto, uma adequação ao status quo, conformando modos de expressão do gênero cabíveis a esta sociedade que constantemente o hierarquiza.

Figura 1: Campanha 1 do perfume Classique de Jean-Paul Gaultier

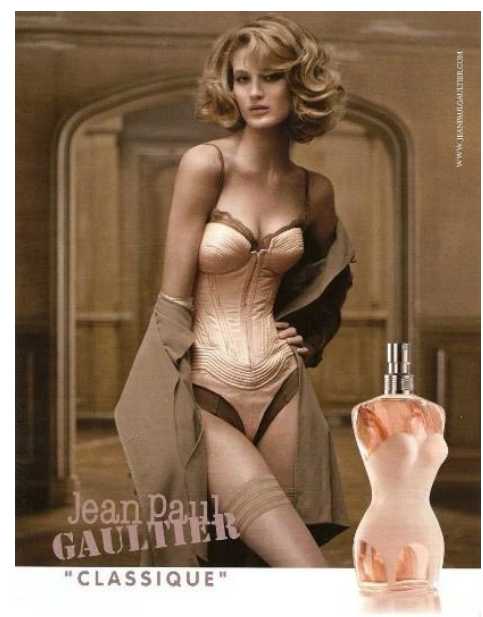

Fonte: Pinterest ${ }^{4}$

Na Figura 1, de uma campanha destinada às mulheres compradoras do perfume Classique, vemos elementos estereotipados de uma feminilidade hegemônica. A modelo apresenta um corpo curvilíneo sob a lingerie, a aparência angelical de um arquétipo eurocêntrico da menina-mulher que esconde a sensualidade na sua delicadeza e inocência, bem como um filtro, utilizado na edição da imagem em tons pasteis, suaves, delicados. Este adorno visual completa-se na montagem da foto em uma proposta vintage que toma, do imaginário popular, a figura da ninfeta. Apoiando-se em Morin (1997), Lindinês Gomes de Barros argumenta que "o corpo ninfético manifesta uma afetividade extrema, com convulsões, paixões, desejos com permanentes delírios, dando a existência e poder ao mito da ninfa na sua imaginação" (2007, p. 34). Tal representação da feminilidade ligada ao afeto extremo, à delicadeza e ao corpo apaixonado dialoga com a Figura 2, em que temos três meninasmulheres, mais uma vez brancas e magras, como se tivessem saído de um mundo onírico, cuja tonalidade rósea no filtro da imagem ressalta o romantismo próprio da representação hegemônica da feminilidade.

\footnotetext{
${ }^{4}$ Fonte: https://br.pinterest.com/pin/364369426092266234/?lp=true. Acesso em 26 de abril de 2019.
} 
Nas duas imagens, destacamos também o design do perfume Classique que não apenas representa o corpo de uma mulher estritamente delineada, mas busca a erotização deste corpo com sua lingerie à mostra. Segundo a pesquisadora Tânia Hoff em entrevista à Revista Contemporânea:

O corpo feminino da publicidade significa, predominantemente, formas: medidas (peso, altura), proporções, sensações, prazer. Máxima expressão da materialidade! O imaginário do corpo feminino foi construído pelo olhar masculino e revelam uma ênfase na visualidade; portanto, faz sentido identificarmos uma objetificação no aspecto físico: determinadas partes têm uma representação bem conhecida pelos homens e também pelas mulheres, o que revela que o imaginário de corpo feminino tem muitos afluentes que ainda significam na rede de sentidos do tecido social (HOFF, 2009, p. 168). ${ }^{5}$

Assim, percebemos uma leitura de corpos femininos baseada em uma cultura heteronormativa, cuja educação dos corpos os submetem a uma lógica construída sob marcas idealizadas pelo (ou para agradar o) homem: erotização, doçura, romantismo, sensibilidade, assim como uma pedagogização das maneiras das mulheres serem interpeladas por posições de sujeitos com sua estética demarcada por corpos magros e brancos, excluindo outras formas de representação (e de existência) de mulheres.

Estas formas midiáticas de construção de gênero é o que a historiadora Teresa de Lauretis denomina de "Tecnologias de Gênero", que exercem o poder de "controlar o campo do significado social e assim produzir, promover e 'implantar' representações de gênero” (1987, p. 228). Para a autora, "toda a arte e a cultura erudita ocidental são um registro da história dessa construção" (p. 209). Portanto, por meio das práticas sociais, históricas, culturais e também pedagógicas, as constituições do "ser homem" e do "ser mulher" (assim, num singular universal) apresentam-se de maneira mutável em um campo de contestações próprio das disputas de narrativas em torno dos sujeitos em sua manifestação discursiva e material. Aqui, cabe questionar, que mulheres cabem no padrão hegemônico (e, praticamente, inalcançável) reforçado pelas campanhas publicitárias analisadas.

Figura 2 - Campanha 2 do perfume Classique de Jean-Paul Gaultier

Fonte: Site OSMOZ6

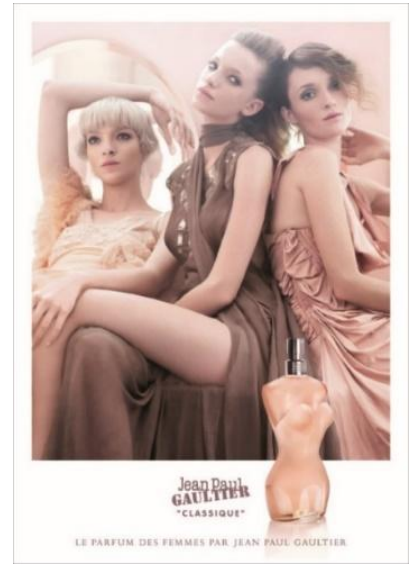

5 "O Corpo da publicidade: ideias e apontamentos de Tânia Hoff". Entrevista concedida à Liliany Samarão. Disponível em: http://www.contemporanea.uerj.br/pdf/ed_12/contemporanea_n12_15_entrevista_liliany.pdf. Acesso em 26 de abril de 2019.

6 Fonte: http://www.osmoz.com.br/Public/Files/_Uploads/images/publicite\%20gaultier\%20classique.jpg. Acesso em 26 de abril de 2019. 
Na Figura 3, encontramos a campanha publicitária do perfume Le Male, direcionado ao público masculino. Por meio de uma análise semiótica, podemos elencar alguns elementos característicos de uma masculinidade hegemônica, como a demonstração atlética do corpo do modelo, sua postura ereta e de braços cruzados, sinalizando um distanciamento em relação ao sujeito que o observa, uma atitude típica de autodefesa, da não abertura às emoções, que seria uma característica atribuída às mulheres e, portanto, negada aos homens. A representação do homem como um marinheiro retoma ao imaginário da figura desbravadora, viril, forte, dos homens que passam longos períodos em alto mar de maneira corajosa e destemida.

Assim, a imagem dialoga com as reflexões de Fernando Seffner quanto às masculinidades hegemônicas representadas. Para o autor, algumas caracterizações em torno deste homem apresentam-se como algo essencial e "[...] um atributo que se presta excepcionalmente para isso é o da atividade, tomada muitas vezes como força, e daí derivando força física, capacidade de decisão, força moral, responsabilidade para assumir grandes empreendimentos, coragem, ser ativo na relação sexual, etc. (2003, p. 123). De acordo com Connel \& Messerschimidt (2013, p. 253):

[...] as masculinidades hegemônicas podem ser construídas de forma que não correspondam verdadeiramente à vida de nenhum homem real. Mesmo assim esses modelos expressam, em vários sentidos, ideais, fantasias e desejos muito difundidos. Eles oferecem modelos de relações com as mulheres e soluções aos problemas das relações de gênero. Ademais, eles se articulam livremente com a constituição prática das masculinidades como formas de viver as circunstâncias locais cotidianas. Na medida em que fazem isso, contribuem para a hegemonia na ordem de gênero societal.

Importante destacarmos que a masculinidade hegemônica, ressaltam os autores, é múltipla e apresenta-se de diferentes maneiras de acordo com o contexto institucional e cultural da sociedade em questão. Porém, aspectos que atravessam estes variados modelos de gênero amparam-se na "ideia original de que a masculinidade hegemônica não necessita ser o padrão comum na vida diária de meninos e homens" (CONNEL \& MESSERSCHIMIDT, 2013, p. 263), sinalizando que estes modos de expressão de gênero não são uma constante no cotidiano social entre os homens, mas símbolos e projetos a serem alcançados/almejados/buscados por meio de sua legitimação e da deslegitimação de outras formas de masculinidade, lidas enquanto subalternas no jogo da hieraquização de gênero. No caso dos perfumes direcionados ao público masculino da grife Jean-Paul Gaultier, são evidenciados elementos próprios da cultura ocidental - especialmente europeia -, branca e binária para a composição das imagens publicitárias, fazendo com que nossos olhares se debrucem sobre a emissão dos significados sociais inteligíveis a esta cultura. 
Figura 3 - Campanha 1 do perfume Le Male de Jean-Paul Gaultier

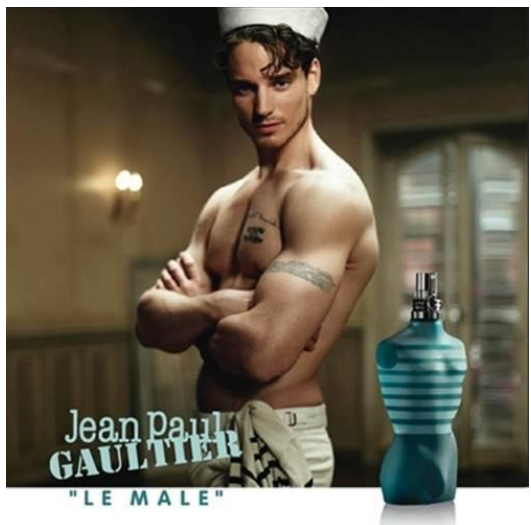

Fonte: Site The Fashionisto ${ }^{7}$

Tais considerações também podem ser encontradas na Figura 4, na qual, além do mesmo conceito de virilidade da imagem anterior alusiva à figura do marinheiro viril, este, por sua vez, apresenta-se no centro, sendo servido por figuras femininas que trabalham, dançam ou pintam a sua tatuagem. Ainda segundo Seffner (2003), um padrão de masculinidade apresenta-se e ele é sustentado pela violência, força física de quem exerce dominação e modos intempestivos de se posicionar nas situações.

Baseado em um conceito de materialização do corpo, temos, assim como o Classique, porém representado de maneira diferente, o design do perfume Le Male, que mostra o corpo masculino com seu peitoral bem delineado. Percebemos, ali, um reforço nas características que diferenciam este homem das particularidades atribuídas às mulheres e ao corpo feminino. Corroborando com esta argumentação, Connel \& Messerschimidt (2013, p. 265) afirmam que "o gênero é sempre relacional e os padrões de masculinidade são socialmente definidos em oposição a algum modelo (quer real ou imaginário) da feminilidade". Logo, a composição relacional se baseia na diferenciação que tais representações fazem entre os homens e as mulheres, evidenciando características, não essencializadas, mas construídas culturalmente para o delineameto das identidades, em função de arranjos sociais atravessados pelas relações de poder vigentes. De acordo com Zago (2009, p. 87), nas performances de masculinidade é tido como importante:

'Definir-se' enquanto homem, exibir suas marcas de homem, aniquilar quaisquer dúvidas sobre a 'definição' de seu sexo e de seu gênero, em primeiro lugar. Definir-se também enquanto corpo, secando-o de gordura e afastando-o da magreza para firmá-lo, afirma-lo, exibi-lo, em suma, para que o próprio corpo diga a 'verdade' do sujeito que nele está encerrado.

Esta encenação repetida dos estereótipos de gênero, neste caso, de uma masculinidade hegemônica sob a égide da cultura ocidental, reforça que a "[...] eficácia de sistemas e regimes de representação reside precisamente em sua capacidade para ocultar sua cumplicidade na constituição,

\footnotetext{
${ }^{7}$ Fonte: https://www.thefashionisto.com/jean-paul-gaultier-2016-le-male-fragrance-campaign/ Acesso em 26 de
} abril de 2019. 
na fabricação do 'real'” (SILVA, 2012, p. 193). Para que a constituição do gênero seja encarada como parte do "real", as normas e as teias discursivas que costuram estas práticas ocultam-se na explicitação da sua intencionalidade, sendo percebidas apenas quando nós nos atentamos na analítica do poder e buscamos as relações entre o que está (e o que não está) sendo representado (e de que forma tais representações são legitimadas ou deslegitimadas). Ainda segundo Tomaz Tadeu da Silva:

\begin{abstract}
A representação é, pois, um processo de produção de significados sociais dos diferentes discursos. Os significados têm, pois, que ser criados. Eles não preexistem como coisas no mundo social. É através dos significados, contidos nos diferentes discursos, que o mundo social é representado e conhecido de uma certa forma, de uma forma bastante particular e que o eu é produzido. E essa "forma particular" é determinada precisamente de relações de poder. O processo de significação é um processo social de conhecimento. (SILVA, 2012, p. 193-194).
\end{abstract}

Ao nos depararmos com a produção de imagens publicitárias, podemos destacar a artilharia das forças de poder interessadas no delineamento das identidades de gênero hegemônicas e de como estas serão representadas, constituindo subjetividades e moldando comportamentos, gestos, formas de falar, se vestir, bem como certos trejeitos nos jogos sociais. Conforme sugere Kellner (2012, p. 117) na sua leitura de imagens, "[...] a publicidade está tão preocupada em vender estilos de vida e em vender posições de sujeito desejáveis, características que são associadas com seus produtos, quanto em vender os próprios produtos", o que denuncia que os jogos de representação que se agrupam nas mídias, em destaque, na publicidade, revestem-se de interesses nas construções simbólicas a captarem e moldarem os desejos do mercado consumidor, atuando de maneira a fomentar as subjetividades que coadunam com a organização social e cultural hegemônica.

Figura 4 - Campanha do perfume Le Male de Jean-Paul Gaultier

Fonte: Pinterest ${ }^{8}$

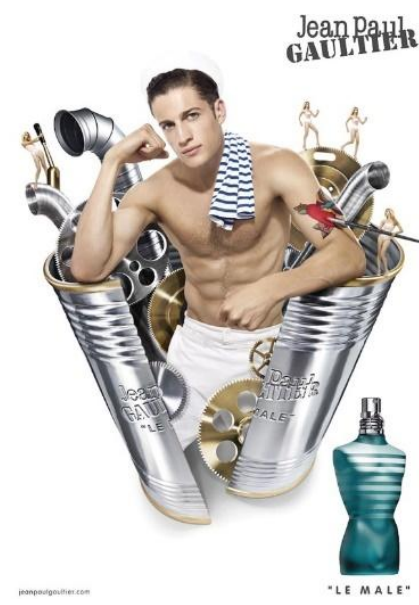

Assim, como pedagogia cultural, a publicidade atua na inscrição de significados e na constituição de papeis entre os sujeitos sociais (STEINBERG, 1997). Segundo Silva \& Bittencourt (2008), o alfabetismo midiático molda os sujeitos e influencia comportamentos, construindo significados

\footnotetext{
${ }^{8}$ Fonte: https://www.pinterest.ch/pin/702772716822125908/ Acesso em 26 de abril de 2019.
} 
diversos. Nas campanhas de Jean-Paul Gaultier, percebemos que os modelos masculinos manifestam virilidade, impetuosidade e agressividade em suas feições e posturas nas fotos, características típicas de uma masculinidade hegemônica (SABAT, 2001). Quanto à campanha destinada às mulheres, destaca-se a sensualidade, a objetificação dos corpos e as tonalidades em cor de rosa. Signos de uma reforçada feminilidade hegemônica esperada de todas as mulheres, excluindo qualquer diferença cabível às variadas identidades e expressões de gênero.

\section{CONSIDERAÇÕES FINAIS}

Neste artigo pudemos identificar que existem padrões de masculinidade e de feminilidade ensinados, reproduzidos e reiterados pelos artefatos culturais, que atuam, de fato, na concepção do que é normal e do que é abjeto, do que é possível e permitido e do que é destoante em nossa sociedade, silenciando as diferenças e reforçando representações estereotipadas. Como relação entre os conceitos e as materialidades apresentadas (SILVA, 1999), as representações de gênero na mídia continuam reforçando a virilidade dos homens e a doçura das mulheres, promovendo a naturalização destes modos de ser no mundo.

Do mesmo modo, podemos dizer que as campanhas publicitárias aqui analisadas, pelo valor que custam os produtos apresentados, voltam-se para uma parcela da população de elevado padrão econômico. Nessa direção, os discursos sinalizados nessas campanhas, voltam-se a mulheres e homens brancos, jovens e de elevado poder aquisitivo. Nesse sentido, (re)produzem um padrão de beleza praticamente inalcançável, talvez porque busquem, exatamente, atuar no campo dos desejos que, por serem inatingíveis, tornam seus/suas consumidores/as, em certa medida, dependentes de, por meio da compra do produto, sentirem-se (pelo menos um pouco) próxima das mulheres angelicais e dos homens viris ali apresentados. Por fim, destacamos a potencialidade dos artefatos culturais como pedagogias que educam, de diversas formas, os modos delimitados por padrões culturais que delimitam as formas (im)possíveis de ser e estar no mundo, que precisam ser questionadas, problematizadas e desnaturalizadas.

\section{REFERÊNCIAS}

1. AMARAL, Marise Basso. Natureza e representação na pedagogia da publicidade. In: COSTA, Marisa Vorraber; VEIGA-NETO, Alfredo; BUJES, Maria Isabel (Orgs.). Estudos Culturais em Educação: Mídia, arquitetura, brinquedo, biologia, literatura, cinema...Porto Alegre: Editora da UFRGS, 2004, p. 143-171.

2. BARROS, Lindinês Gomes de. O erotismo mítico da ninfeta. 2007. 104p. Dissertação (Mestrado em Ciências Sociais) - Universidade Federal do Rio Grande do Norte, Natal. 
3. BUTLER, Judith. Actos performativos e constituição de género. Um ensaio sobre fenomenologia e teoria feminista. In: MACEDO, Ana Gabriela; RAYNER, Francesca (Orgs.). Gênero, cultura visual e performance. Antologia crítica. Minho: Universidade do Minho/Húmus, 2011.

4. Problemas de gênero: feminismo e subversão da identidade. Tradução de Renato Aguiar. 16 ed. Rio de Janeiro: Civilização Brasileira, 2018.

5. CAMPELO, Cleide Riva. O corpo e seus textos. In: CAMPELO, Cleide Riva. Cal(e)idoscorpos: um estudo semiótico do corpo e seus códigos. São Paulo: Annablume, 1996.

6. CONNEL, Robert W.; MESSERSCHMIDT, James W. Masculinidade hegemônica: repensando o conceito. Estudos Feministas, Florianópolis, v. 21, n. 01, jan./abr. 2013. ISSN: 0104-026X. Disponível em: http://www.scielo.br/pdf/ref/v21n1/14.pdf. Acesso em: 06 ago. 2019. Doi: http://dx.doi.org/10.1590/S0104-026X2013000100014.

7. COSTA, Marisa Vorraber; ANDRADE, Paula Deporte de. Na produtiva confluência entre educação e comunicação, as pedagogias culturais contemporâneas. PERSPECTIVA, Florianópolis, v. 33, n. 2, $2015 . \quad$ ISSN: 2175-795x. Disponível em: https://periodicos.ufsc.br/index.php/perspectiva/article/view/2175-795X.2015v33n2p843/31267. Acesso em: 06 ago. 2019. Doi: https://doi.org/10.5007/2175-795X.2015v33n2p843.

8. DANIEL, Laene Mucci; AMODEO, Nora Presno. A classificação da Publicidade e o discurso publicitário como fatores de construção das representações do rural. Intercom - Rev. Bras. Ciênc. Comum. [online], v. 37, n. 1, jan./jun. 2014. ISSN: 1809-5844. Disponível em: http://www.scielo.br/pdf/interc/v37n1/a12v37n1.pdf. Acesso em: 06 ago. 2019. Doi: http://dx.doi.org/10.1590/S1809-58442014000100012.

9. DAOLIO, Jocimar. Da cultura do corpo. Campinas, SP: Papirus, 1995.

10. FOUCAULT, Michel. A ordem do discurso. Tradução de Laura Fraga de Almeida Sampaio. São Paulo: Edições Loyola, 1996.

11. GOELLNER, Silvana Vilodre. A produção cultural do corpo. In: LOURO, Guacira Lopes; FELIPE, Jane; GOELLNER, Silvana Vilodre (Orgs.). Corpo, gênero e sexualidade: um debate contemporâneo na educação. 9 ed. Petrópolis, RJ: Vozes, 2003.

12. KELLNER, Douglas. Lendo imagens criticamente: em direção a uma pedagogia pós-moderna. In: SILVA, Tomaz Tadeu da (Org.). Alienígenas na sala de aula: uma introdução aos estudos culturais em educação. 10 ed. Petrópolis, RJ: Vozes, 2012 (Coleção Estudos Culturais em Educação). 
LAURETIS, Teresa de. A tecnologia do gênero. Disponível em: http://marcoaureliosc.com.br/cineantropo/lauretis.pdf. Acesso em: 26 abr. 2019.

14. LOURO, Guacira Lopes. Gênero, sexualidade e educação: uma perspectiva pós-estruturalista. Petrópolis, RJ: Vozes, 1997.

15. SABAT, Ruth. Pedagogia cultural, gênero e sexualidade. Estudos Feministas, Santa Catarina, n. 09, n. $01, \quad 2001 . \quad$ ISSN: 1806-9584. Disponível em: https://periodicos.ufsc.br/index.php/ref/article/view/S0104-026X2001000100002. Acesso em: 06 ago. 2019. Doi: https://doi.org/10.1590/S0104-026X2001000100002.

SEFFNER, Fernando. Derivas da masculinidade: representação, identidade e diferença no âmbito da masculinidade bissexual. 2003. 261p. Tese (Doutorado em Educação) - Universidade Federal do Rio Grande do Sul, Porto Alegre.

17. 17. SILVA, Tomaz Tadeu da. A produção social da identidade e da diferença In: (org.). Identidade e diferença: a perspectiva dos Estudos Culturais. Petrópolis, RJ: Vozes, 2014. p. 73102. . Currículo e identidade social: territórios contestados. In: SILVA, Tomaz Tadeu da (Org.). Alienígenas na sala de aula: uma introdução aos estudos culturais em educação. 10 ed. Petrópolis, RJ: Vozes, 2012 (Coleção Estudos Culturais em Educação).

19. SILVA, Thaíse da; BITTENCOURT, Zoraia Aguiar. Da produção de múltiplos alfabetismos ao alfabetismo midiático. In: TRINDADE, lole Maria Faviero (Org.). Múltiplas alfabetizações e alfabetismos. Porto Alegre: Editora da UFRS, 2008.

20. STEINBERG, Shirley. Kindercultura: A construção da infância pelas grandes corporações. In: SILVA, L. H.; AZEVEDO, J. C.; SANTOS, E. S. Identidade social e a construção do conhecimento. Porto Alegre: Ed. SMED, 1997. p. 98-145.

21. ZAGO, Luiz Felipe. Masculinidades disponíveis.com: sobre como dizer-se homem gay na internet. 2009. 227p. Dissertação (Mestrado em Educação) - Universidade Federal do Rio Grande do Sul, Porto Alegre.

\section{Alcidesio Oliveira da Silva Junior}


Mestrando em Educação na linha de Estudos Culturais da Educação (PPGE/UFPB), integrante do Grupo de Pesquisa Gênero, Educação, Diversidade e Inclusão (GEDI/PPGE/UFPB) e do Laboratório de Experiência, Visualidade e Educação (LEVE/UFPE).

\section{Jeane Félix}

Professora Adjunta vinculada ao Departamento de Habilitações Pedagógicas e ao Programa de Pósgraduação em Educação do Centro de Educação da Universidade Federal da Paraíba na linha dos Estudos Culturais da Educação. Coordenadora do Grupo de Pesquisa Gênero, Educação, Diversidade e Inclusão (GEDI/PPGE/UFPB).

\section{Como citar este documento:}

OLIVEIRA DA SILVA JUNIOR, Alcidesio; FÉLIX, Jeane. Publicidade como Pedagogia Cultural: representações de gênero nas campanhas de Jean-Paul Gaultier. Reflexão e Ação, Santa Cruz do Sul, v. $28, \quad$ n. 2, jun. 2020. ISSN 1982-9949. Disponível em: <https://online.unisc.br/seer/index.php/reflex/article/view/14051>. Acesso em: doi:https://doi.org/10.17058/rea.v28i2.14051. 